\title{
Naturaleza jurídica de los efectos del convenio arbitral
}

\author{
Oswaldo Santos Dávalos* \\ Recibido/Received: 21/07/2017 \\ Aceptado/Accepted: 24/07/2017
}

SUMARIO: 1. Introducción. 2. La "renuncia" a la jurisdicción ordinaria. 2.1 ¿Qué es una renuncia? 2.2 Suscribir un convenio arbitral no acarrea una renuncia. 3. ¿Genera el convenio arbitral una obligación de hacer? 3.1 ¿Es cierto que el convenio arbitral genera obligaciones de hacer? 3.2 ¿Qué pasa si se incumple una obligación de hacer? 4. ¿Genera el convenio arbitral obligaciones de no hacer? 4.1 ¿Qué pasa si se incumple una obligación de no hacer? 4.2 ¿Por qué el convenio arbitral no genera obligaciones negativas? 5. ¿Qué son los derechos potestativos? 5.1 Diferencias entre derechos de crédito y derechos potestativos. 5.2 Clases de derechos potestativos. 6. El convenio arbitral genera derechos potestativos. 7. ¿Qué implica que el convenio arbitral genere derechos potestativos? 8. Resumen y conclusiones.

PALABRAS CLAVE: arbitraje, convenio arbitral, obligaciones, derechos de crédito, renuncia, derechos absolutos, derechos potestativos.

KEYWORDS: arbitration, arbitration agreement, obligations, waiver of rights, absolute rights, rights in personam.

* Socio de Santos Burbano de Lara, Profesor titular de la Universidad San Francisco de Quito. Este artículo se basó en la monografía final presentada dentro de la especialización superior en métodos alternativos de solución de conflictos que el autor cursó en la Universidad Andina Simón Bolívar. 
RESUMEN: en este artículo se analiza la naturaleza de los efectos derivados de suscribir un convenio arbitral. Se expone por qué, bajo el Derecho ecuatoriano, el convenio arbitral no genera obligaciones. También se explica por qué suscribir un convenio arbitral no supone renunciar a acudir ante la justicia estatal. Finalmente, se explica por qué el convenio arbitral genera derechos potestativos.

ABSTRACT: this article studies the legal nature of the effects arising out of an arbitration agreement. We explain why, under Ecuadorean law, an arbitration agreement creates no obligations and why it does not entail a waiver of the right to have recourse to the state's judiciary. We propose a different explanation, which, in our view, accurately describes the nature of those consequences.

\section{INTRODUCCIÓN}

El arbitraje encuentra su justificación en la voluntad de los particulares de someter sus controversias a la decisión de terceros escogidos de común acuerdo ${ }^{1}$. Esa voluntad se manifiesta a través del convenio arbitral. Es por eso que el convenio arbitral es capital en la vida del arbitraje ${ }^{2}$.

Suscribir un convenio arbitral acarrea una serie de efectos de importancia. Atribuye competencia al árbitro o a los árbitros que serán designados. También faculta a su suscriptor a enervar la pretensión de la otra parte si esta acude a la justicia estatal para resolver un diferendo cobijado por dicho convenio, entre otros efectos.

En este artículo buscaremos determinar cuál es la naturaleza jurídica de la facultad que tiene el suscriptor de un convenio arbitral para impedir que prospere el proceso iniciado por la otra

1. R. CAIVAno, La cláusula arbitral. Evolución histórica y comparada. Colección textos de jurisprudencia, Bogotá, 2008, p. 21.

2. Ibídem. 
parte ante la justicia ordinaria. No hay discusión sobre cuáles son los efectos prácticos de esa facultad ni sobre cómo describir los efectos del convenio arbitral, pero sí hay distintos puntos de vista sobre cómo categorizarlos jurídicamente. En nuestra opinión, entender en qué consisten los efectos del convenio arbitral tiene una importancia indiscutible en la comprensión del arbitraje.

Se ha dado algunas explicaciones sobre la naturaleza jurídica de los efectos del convenio arbitral. Así, según se dice, el convenio arbitral (i) implica una renuncia a acudir a la jurisdicción estatal; (ii) genera la obligación de acudir a arbitraje o (iii) crea la obligación de no acudir ante la jurisdicción ordinaria. Analizaremos esas posiciones a la luz del Derecho ecuatoriano. También expondremos nuestra propia tesis. Consideramos que el convenio genera derechos potestativos; no implica renuncia alguna, ni supone el nacimiento de obligaciones. Explicaremos cuáles son los fundamentos de nuestra posición y por qué consideramos que brinda una explicación satisfactoria.

\section{LA "RENUNCIA" A LA JURISDICCIÓN ORDINARIA}

Se ha dicho que la suscripción de un convenio arbitral implica renunciar a acudir ante la jurisdicción ordinaria. En virtud de la cláusula compromisoria las partes

[D]eciden someter algunos asuntos a arbitraje, sustrayéndolos al conocimiento de los jueces ordinarios. Las partes renuncian a que esos asuntos sean decididos por los tribunales de justicia, asignándoselos a particulares, a quienes invisten, como consecuencia de ello, de funciones y facultades jurisdiccionales ${ }^{3}$.

En caso de producirse un diferendo incluido en el convenio arbitral, "ya no existe para las partes la libertad de optar por accionar en la justicia estatal. Quedan obligados a solucionarlo por la vía arbitral $[\ldots]^{\prime \prime}$. Para TALERO RUEDA

3. R. CaIVAno, Arbitraje, Ad-hoc, 2000, p. 115.

4. Ídem, p. 116. 
[E]l pacto arbitral denota la voluntad de las partes, en el sentido de acudir exclusivamente al mecanismo arbitral para resolver sus diferencias. Ello significa que éstas, sin prescindir de la asistencia de las cortes de la justicia estatal, renuncian a ventilar los méritos de la controversia ante dichas cortes ${ }^{5}$.

Nuestra jurisprudencia ha sido diáfana al respecto. En sus palabras, "la celebración del convenio arbitral impide a las partes someter el caso a la justicia estatal"6.

Nuestra Ley de Arbitraje y Mediación (LAM) también acoge esa terminología en más de una ocasión. Primero, al enumerar los requisitos que debe cumplir el convenio arbitral suscrito con una entidad pública; luego, al enunciar cuáles son los efectos de tal convenio. El literal d) del artículo 4 de la LAM dispone que "[e]l convenio arbitral, por medio del cual la institución del sector público renuncia a la jurisdicción ordinaria, deberá ser firmado por la persona autorizada para contratar a nombre de dicha institución". Más adelante, su artículo 7 establece que el acuerdo arbitral "impide someter el caso a la justicia estatal" y obliga a las partes a acatar el laudo que se expida.

Por tanto, para quienes sostienen esta tesis, celebrar un convenio arbitral trae como consecuencia el que las partes no tengan más alternativa que acudir a arbitraje en caso de presentarse una controversia. Por eso, según GUASP, citado por AYLWIN AZÓcAR, la excepción que se puede deducir en caso de que la otra parte acuda ante la justicia estatal "no es de incompetencia ni de litispendencia, sino de renuncia al conocimiento de la controversia por la autoridad judicial $[\ldots]^{\prime \prime 7}$.

A continuación haremos mención a la institución jurídica de la renuncia. Después explicaremos por qué, en nuestra opinión, la celebración de un convenio arbitral no supone renuncia alguna a la jurisdicción estatal.

5. S. TAlero Rueda, Arbitraje comercial internacional. Instituciones básicas y derecho aplicable. Universidad de los Andes, 2008, p. 85.

6. Primera Sala de lo Civil y Mercantil de la Corte Suprema de Justicia, Resolución No. 261. RO No. $262,29 / 01 / 2004$.

7. G. Chiovenda. Citado por P. Aylwin Azócar, El juicio arbitral, Jurídica de Chile, 2005, p. 286. 


\section{1 ¿Qué es una renuncia?}

Nuestro Código Civil no contiene definición alguna de renuncia. Empero, su artículo 11 dispone que los derechos son renunciables por regla general. Son irrenunciables solo aquellos derechos que la ley ha declarado como tales y aquellos que no miran al solo interés del renunciante. Reza el Código que "[p]odrán renunciarse los derechos conferidos por las leyes, con tal que sólo miren al interés individual del renunciante, y que no esté prohibida su renuncia".

Dado que no existe una definición legal de "renuncia", es menester entender tal palabra en su sentido natural y obvio, según prescribe el numeral segundo del artículo 18 del Código Civil. El Diccionario de la Real Academia de la Lengua define "renuncia" como "[h]acer dejación voluntaria, dimisión o apartamiento de algo que se tiene, o se puede tener". Para CABANELLAS, la renuncia es la dejación voluntaria y consciente que uno hace de una cosa, de un derecho, de una acción o de un privilegio que se tiene adquirido o reconocido a su favor. Es una disminución del patrimonio o una dejación de potestades ${ }^{8}$.

\subsection{Suscribir un convenio arbitral no acarrea una renuncia}

En nuestra opinión, hay dos razones para pensar que el convenio arbitral no entraña renuncia alguna. La primera es que la renuncia de los derechos absolutos es un acto jurídico unilateral, por lo que no se explica que tenga como causa eficiente un acto bilateral, como es el convenio arbitral. La segunda razón es que el convenio arbitral necesariamente debe generar derechos ya que es posible renunciar a él.

La renuncia a acudir a los jueces es un acto unilateral

El derecho a acceder ante la justicia estatal es un derecho que tienen los particulares frente a todos los demás. Todos los sujetos 8. G. Cabanellas, Diccionario enciclopédico de Derecho usual, Heliasta, 2008, p. 154. 
están obligados a respetar (y a no poner trabas) a ese derecho. Eso quiere decir que el derecho a la tutela judicial efectiva es un derecho subjetivo no patrimonial y absoluto. Los derechos subjetivos absolutos son los que se tienen sin respecto a determinada persona, como ocurre con los derechos reales.

En cambio, los derechos subjetivos relativos se tienen con respecto a determinada persona, como es el derecho que tienen los cónyuges a guardarse fe o el derecho que tiene el comodante a que se le restituya el comodato.

No hay discusión de que la renuncia a los derechos subjetivos absolutos requiere de la sola voluntad de su titular, como ocurre con la renuncia a los derechos reales. Sería un absurdo exigir que el titular requiera de la aquiescencia de todos los "sujetos pasivos" de ese vínculo jurídico, cuando esos derechos se ostentan sin respecto a determinada persona.

Por lo tanto, la renuncia a acceder a la justicia estatal necesariamente debería tener como causa un acto unilateral. Siendo así, no tiene justificación alguna pensar que la causa eficiente de esa renuncia pueda ser un negocio jurídico bilateral. Por lo tanto, estimamos que el convenio arbitral, que es un acto bilateral, no puede servir de causa eficiente para disponer de un derecho cuya renuncia requiere de un acto jurídico esencialmente unilateral ${ }^{9}$.

Si se puede renunciar al convenio arbitral, es porque genera derechos

El segundo argumento para sostener que el convenio arbitral no implica renunciar a un derecho es que este necesariamente debe crear -y no extinguir- un derecho. Todo eso sigue de la posibilidad de renunciar al convenio arbitral. La premisa de la que partimos es sencilla: para poder renunciar a un derecho es nece-

9. A pesar de que no es materia de nuestro trabajo, cabe resaltar la tutela judicial efectiva es un derecho constitucional y que todos los derechos constitucionales son irrenunciables. Por lo tanto, habría razones para pensar que una renuncia a acceder ante los jueces carecería de validez. También se debe acotar que un acto bilateral puede obligar a las partes a renunciar a algo. En ese caso, se trataría de una obligación de hacer jurídico. Esa obligación tendría por objeto una prestación consistente en extinguir un derecho. 
sario ser su titular. La renuncia implica un acto de disposición y no se puede disponer de lo que no se tiene.

Según lo reconocen la jurisprudencia, la legislación y la doctrina, se puede renunciar al convenio arbitral. Así, para AYLWIN AzócAR, la suscripción de un convenio arbitral supone la pérdida de jurisdicción de los tribunales estatales. El mismo autor agrega que esa "falta de jurisdicción [...] puede ser renunciada por las partes en cualquier momento de común acuerdo [... $]^{\prime \prime 10}$. Para CHILLÓN MEDINA, "[e]l arbitraje, en cuanto encuentra un fundamento en el pacta sunt servanda, es un derecho renunciable en sus propios términos [...], ya que su exclusión no contraría al interés o al orden público"11.

La posibilidad de renunciar al convenio arbitral está expresamente reconocida en el artículo 8 de nuestra LAM, que reza que "[1]as partes pueden de mutuo acuerdo renunciar por escrito al convenio arbitral que hayan celebrado, en cuyo caso cualesquiera de ellas puede acudir con su reclamación al órgano judicial competente".

En Derecho comparado la situación es similar. La Ley de Arbitraje guatemalteca dispone en su artículo 11 que "[s]e entenderá que las partes renuncian al arbitraje y se tendrá por prorrogada la competencia de los tribunales cuando el demandado omita interponer la excepción de incompetencia". El artículo 38 de la Ley de Arbitraje y Mediación nicaragüense dispone que las partes pueden renunciar al arbitraje mediante convenio expreso, renuncia tácita o "cuando se inicie causa judicial por una de las partes y el demandado no invoque la excepción arbitral dentro de los plazos previsto (sic) para casa proceso".

En consecuencia, el convenio arbitral debe generar un derecho renunciable. Además, necesariamente debe ser un derecho relativo. Si el convenio arbitral genera un derecho entre las partes,

10. P. Aylwin Azócar, N. 7, p. 284.

11. J. Chillón Medina y J. Merino Marchán, Tratado de arbitraje privado interno e internacional. Civitas, 1991, p. 269. 
no puede decirse que su único efecto sea extinguir un derecho. Si fuera cierto que el solo efecto del convenio arbitral consiste en renunciar a un derecho, una vez celebrado ese convenio ya no habría ya a qué renunciar.

Como conclusión, el convenio arbitral trae como consecuencia el nacimiento de un derecho. Siendo así, no es posible que el único efecto del convenio arbitral sea la pérdida o renuncia de un derecho. Por ese motivo, consideramos que se debe descartar la tesis que sostiene que el efecto exclusivo del convenio arbitral es renunciar a la justicia ordinaria.

\section{3. ¿GENERA EL CONVENIO ARBITRAL UNA OBLIGACIÓN DE HACER?}

Otra tesis sostiene que el convenio arbitral obliga a las partes a someter a arbitraje toda controversia que se encuentre cobijada por él. Para GonZÁlez DE Cossío, "[e]l efecto principal del acuerdo arbitral es obligar a las partes a recurrir al arbitraje para resolver todas sus diferencias"12. En la misma línea, SALCEDO VERDUGA asevera que el convenio arbitral obliga a las partes "a someter sus diferencias a arbitraje, obligación que, por lo tanto, tiene como origen el convenio arbitral"13. CAIVANO aduce una vez producido un conflicto amparado por el convenio arbitral, "ya no existe para las partes la libertad de optar por accionar en la justicia estatal $[\ldots]^{\prime \prime 14}$.

Esa tesis postula que en el caso de presentarse un conflicto que esté sujeto a la cláusula arbitral, las partes tienen la obligación de resolverlo mediante arbitraje. En nuestra opinión, es discutible que eso ocurra en el Derecho ecuatoriano. En nuestro ordenamiento, el convenio arbitral tampoco genera obligaciones de hacer.

12. F. González de Cossío, Arbitraje, Porrúa, 2008, p. 132.

13. E. Salcedo Verduga, El arbitraje. La justicia alternativa, 2da. Ed., Distrilib, 2007, p. 109.

14. R. CAIVANO, N. 3, p. 116. 


\section{1 ¿Es cierto que el convenio arbitral genera obligaciones de hacer?}

Consideramos que hay dos razones que desvirtúan la posibilidad de que el convenio arbitral genere obligaciones de hacer (en nuestro país, al menos). La primera es que no es cierto que se incumpla con el convenio arbitral al no acudir a arbitraje. La segunda razón es que nuestro ordenamiento trata al "incumplimiento" del convenio arbitral de manera muy distinta que al incumplimiento de las obligaciones de hacer; la diferencia es tan grande que no resulta plausible pensar que los efectos del convenio arbitral pueden clasificarse como obligaciones de ese tipo.

Para explicar nuestra posición es necesario que primero nos refiramos al concepto de obligación, expliquemos cuáles son sus clases dependiendo de cuál sea su prestación, y cuál es su naturaleza jurídica. También será necesario que nos refiramos al régimen previsto en nuestra normativa para el cumplimiento forzado de las obligaciones de hacer. Esta explicación nos ayudará también al exponer nuestra tesis de por qué el convenio arbitral no genera obligaciones de no hacer, que abordaremos más adelante.

Dice ABELIUK que la definición más corriente de obligación la considera un "vínculo jurídico entre personas determinadas, en virtud del cual una de ellas se coloca en la necesidad de efectuar a la otra una prestación que puede consistir en dar una cosa, hacer o no hacer algo"15. Para LlAMBíAs, obligación "es la relación jurídica en virtud de la cual alguien denominado deudor debe satisfacer una prestación a favor de otro llamado acreedor. Acreedor y deudor son los protagonistas que dominan la escena del derecho de las obligaciones"16. Además, es esencial a la obligación el elemento responsabilidad, es decir, que el deudor comprometa todo su patrimonio embargable para garantizar el cumplimiento de la obligación. Se lo denomina "derecho de prenda general", y en virtud de este "el patrimonio del deudor está asegurando que,

15. R. Abeliuk, Las obligaciones, Jurídica de Chile, v. I, 1993, p. 29.

16. J. J. LlambÍAs, Código civil anotado: doctrina, jurisprudencia, Abeledo-Perrot, tomo II.A, 1989-1992, p. 11. 
si no voluntariamente, cuando menos forzadamente o por equivalencia, se cumplirá su obligación"17.

La obligación es el aspecto pasivo del derecho de crédito. Como reza el Código Civil, los derechos personales son los que solo

pueden reclamarse de ciertas personas que, por un hecho suyo o la sola disposición de la ley, han contraído las obligaciones correlativas; como el que tiene el prestamista contra su deudor, por el dinero prestado, o el hijo contra el padre por alimentos $[\ldots]^{18}$.

Se incumple una obligación cuando no se observa la prestación respectiva. Así, si el comprador no paga el precio, si el comodatario no restituye el comodato o si el arrendatario no paga el canon de arrendamiento, incumplen con sus respectivas obligaciones.

Sucede lo mismo con las obligaciones que consisten en hacer alguna cosa. Si una persona se compromete a construir un muro, incumplirá su obligación si no construye el muro en el tiempo y forma debidos; si un mandatario se compromete a realizar una gestión a nombre del mandante y no lo hace, no habrá observado su prestación tampoco.

Si el convenio arbitral generara obligaciones de hacer, las partes las incumplirían si es que no hicieran aquello a lo que están obligadas. Por tanto, si tal obligación de hacer consistiera en acudir a arbitraje de producirse un diferendo amparado por la cláusula, las partes incumplirían por el solo hecho de no acudir a arbitraje.

En nuestra opinión, no es verosímil sostener que se "incumple" el convenio arbitral si es que no se acude a arbitraje. Supongamos que las partes de un contrato de compraventa suscriben

18. Código Civil, Art. 596, RO Sup. No. 46, 24/06/2005. 
un convenio arbitral para amparar las controversias derivadas de ese contrato. Supongamos que el comprador incumple su obligación de pagar el precio y que el vendedor decide no demandar por considerar que los costos de iniciar un arbitraje superarían el beneficio que podría recibir en caso de obtener un resultado favorable. ¿Podría decirse que el vendedor "incumplió" el convenio arbitral por no acudir a arbitraje? Como es obvio, no.

Si el convenio arbitral genera obligaciones de hacer, no acudir a arbitraje supondría un incumplimiento. Siendo así, si no se acudiera a arbitraje, ¿se verificaría la condición resolutoria tácita? ¿Podría la parte "cumplida" ejercer la acción resolutoria o la acción de cumplimiento forzoso del convenio arbitral? ¿Aplicaría la excepción de contrato no cumplido? Consideramos que la respuesta es negativa.

Hay quienes sostienen que el estar obligado a acudir a arbitraje es lo mismo que estar obligado a no acudir ante la justicia ordinaria. Se entiende que estar obligado a no ir ante la justicia ordinaria vendría a ser lo mismo que estar obligado a acudir a arbitraje.

En nuestro sentir, estar obligado a acudir a arbitraje no es lo mismo que estar obligado a no acudir ante la jurisdicción estatal. Los efectos de esa clase de obligaciones son distintos: si el convenio obligara a las partes a no acudir ante la jurisdicción estatal, tendría un efecto distinto que si las obligara a acudir a arbitraje.

El efecto de estar obligado a iniciar un arbitraje sería el mismo que el efecto de no ir a la justicia estatal si y solo si tales alternativas fueran exhaustivas, es decir, si acudir a la justicia ordinaria o al arbitraje fueran las únicas alternativas del suscriptor de un convenio arbitral. Sin embargo, ese es un falso dilema. Es un falso dilema porque, como explicamos, el suscriptor de un convenio arbitral tiene más alternativas a más de las ya mencionadas en el caso de presentarse una controversia amparada por la cláusula: el acreedor sencillamente puede optar por no exigir su derecho, iniciar una negociación, condonar la deuda, etc. 
Hay otra razón para pensar que la naturaleza jurídica de los efectos del convenio arbitral es distinta a una obligación de hacer. Para explicarlo tenemos que referirnos al régimen de cumplimiento forzado de ese tipo de obligaciones.

\section{2 ¿Qué pasa si se incumple una obligación de hacer?}

Según reza el artículo 1569 del Código Civil, si la obligación es de hacer, y el deudor se constituye en mora, el acreedor puede optar, a más de la respectiva indemnización, por cualquiera de las siguientes alternativas.

- Que se le autorice a hacer ejecutar la obligación a un tercero, a cargo del deudor; o,

- Que el deudor lo indemnice por los perjuicios derivados del incumplimiento del contrato.

También existe un régimen para el cumplimiento forzado de las obligaciones de hacer jurídico, es decir aquellas cuya prestación consiste en la celebración o en el otorgamiento de un acto jurídico. Según el Código Orgánico General de Procesos (COGEP), si el hecho debido consistiere en el otorgamiento y suscripción de un instrumento, lo hará el juez en representación del que deba realizarlo ${ }^{19}$. Por tanto, si el deudor de una obligación de hacer jurídico incumple su obligación, el juez puede celebrar el acto en su nombre.

Si el convenio arbitral generara obligaciones de hacer, como dicho hacer consistiría en la realización de un acto jurídico procesal, se llegaría a la inverosímil conclusión de que su cumplimiento forzado consistiría en que sea el juez quien suscriba el acto jurídico procesal respectivo a nombre del "deudor".

Pero hemos visto que si el "deudor" "incumple" con el convenio arbitral, la solución que prevé el ordenamiento es muy distinta a que el juez "cumpla" a su nombre.

19. Código Orgánico General de Procesos (COGEP), Art. 368 in fine, RO Sup. No. 506, 22/05/2015. 
Es tan sencillo como que las partes del convenio arbitral no tienen modo alguno de forzar a la otra a acudir a arbitraje. Como dice REDFERN, en caso de no cumplir con el convenio arbitral, "an order for specific performance is equally impracticable, since a party cannot be compelled to arbitrate if it does not wish to do $\mathrm{so}^{\prime 20}$. Lo que las partes pueden hacer es crear a la otra la carga procesal de comparecer ante un proceso arbitral, cuando se la cite con la demanda respectiva. El suscriptor de un convenio arbitral puede, además, enervar la acción de su contraparte, si es que esta hubiere acudido con su demanda ante la justicia estatal. Pero no puede hacer más.

Por tanto, concluimos que el convenio arbitral no genera obligaciones de hacer, por dos motivos: porque es un sinsentido sostener que se incumple con el convenio arbitral si no se acude a arbitraje, y porque el régimen para el cumplimiento forzado de las obligaciones de hacer es distinto al régimen previsto para el caso de que el suscriptor de un convenio arbitral acuda ante la justicia estatal.

A continuación explicaremos por qué el convenio arbitral tampoco genera obligaciones de no hacer. Expondremos cuáles son las razones por las que, en nuestro criterio, a pesar de que el suscriptor de un convenio arbitral puede impedir que prospere el juicio iniciado por su contraparte ante la justicia estatal, tampoco estamos en presencia de obligaciones negativas.

\section{4. ¿GENERA EL CONVENIO ARBITRAL OBLIGACIONES DE NO HACER?}

Las obligaciones de no hacer son aquellas cuya prestación consiste en una abstención a cargo del deudor. La obligación de no hacer -dice MEZA BARROS- "consiste en que el deudor se abstenga de un hecho que, de otro modo, le sería lícito ejecutar" ${ }^{\prime 21}$. Se las califica como obligaciones negativas, ya que implican que el

20. A. Redfern y M. Hunter, Law and Practice of International Commercial Arbitration, Sweet and Maxwell, Londres, 1999, p. 7.

21. R. Meza Barros, Manual de derecho civil: de las obligaciones, Jurídica de Chile, 2001, p. 28. 
deudor no realice alguna determinada conducta. Al igual que las obligaciones de hacer, y a pesar de que no es una distinción reconocida por la doctrina, es dable distinguir entre las obligaciones de no hacer material y las obligaciones de no hacer jurídico.

Como su nombre lo indica, las obligaciones de no hacer material son aquellas cuya prestación consiste en la no realización de un hecho distinto a un acto jurídico, como podrían serlo, a manera de ejemplo, no escuchar música en altoparlantes a altas horas de la noche, no construir edificación alguna en una determinada área, etc.

Las obligaciones de no hacer jurídico consisten en la no celebración o en el no otorgamiento de un acto jurídico. Por ejemplo, obligaciones de no hacer jurídico son aquellas consistentes en no otorgar testamento, no contratar a cierto trabajador, no presentar una determinada demanda, etc.

Se sostiene que el convenio arbitral obliga a las partes a no acudir ante la jurisdicción estatal. A diferencia de la tesis que acabamos de exponer, esta tesis implicaría que el deudor está obligado a no realizar un determinado acto, en particular, en no acudir con su demanda ante los jueces ordinarios. Se diferencia con la tesis de la renuncia, porque en esta sí se genera un derecho como contrapartida de la supuesta de la obligación de no hacer; y se diferencia de la segunda tesis porque la prestación objeto de la obligación consiste en un no hacer jurídico, mientras que la prestación objeto de la obligación, según la primera tesis, consiste en un hacer jurídico.

\section{1 ¿Qué pasa si se incumple una obligación de no hacer?}

Existen algunas diferencias entre el régimen jurídico del cumplimiento forzado de las obligaciones de hacer y el de las obligaciones de no hacer. Uno de ellos es que en las obligaciones negativas no es necesario constituir en mora al deudor ${ }^{22}$; otra di22. Código Civil, Art. 1572, No. 46, 24/06/2005. 
ferencia es que las obligaciones de no hacer no pueden ser cumplidas por un tercero ${ }^{23}$, etc.

El régimen del cumplimiento forzado de las obligaciones de no hacer material es también particular. Según el artículo 1571 del Código Civil, la respuesta depende de si es que la cosa hecha en contravención de la obligación puede o no deshacerse. Si no puede deshacerse, el deudor debe resarcir al acreedor; si puede deshacerse y su destrucción es necesaria, el deudor está obligado a destruirla; si puede deshacerse y su destrucción no es necesaria, debe cumplirse con la obligación por otros medios.

Como dice AbELIUK,

[1]a infracción de la obligación de no hacer presenta también particularidades, porque se traducirá en deshacer lo hecho, siempre que sea posible y necesario. La contravención es una actuación que no podía hacerse; se trata, pues, de restablecer la situación tal como si no hubiera existido incumplimiento ${ }^{24}$.

Por tanto, en principio, si se incumple con una obligación de no hacer, el acreedor está facultado a deshacer aquello que el deudor hubiere hecho en contravención de su obligación.

No se prevé un régimen de cumplimiento forzado en el caso de las obligaciones de no hacer jurídico, como ocurriría si un franquiciante celebrara un contrato de franquicia habiéndose obligado con otro franquiciado a no celebrar otro contrato de esa naturaleza.

Consideramos que el postulado de la relatividad de los negocios jurídicos constituye un límite infranqueable a todo intento de hacer valer una obligación de no hacer jurídico frente a terceros. El postulado de la relatividad de los negocios jurídicos (res inter alios acta aliis neque nocere neque prodesse potest) quiere decir que estos "no perjudican ni aprovechan a los terceros", por regla

23. Si alguien se compromete a que un tercero no haga algo, con la salvedad de la promesa por otro, se trataría de una obligación de hacer: impedir que algo suceda.

24. R. AbeliuK, N. 15, Tomo II, p. 664. 
general ${ }^{25}$. Si los actos jurídicos no surten efectos sino con respecto a las partes que hubieren intervenido en ellos, la estipulación de un acto no tendría por qué tener efecto alguno en otro, en principio. Siendo así, una estipulación en un contrato que prohíba a una de las partes celebrar otro no tiene por qué alcanzar terceros.

Además, no hay sustento doctrinario o legal alguno para sostener que la contravención de una obligación de no hacer sea una causal para resolver, rescindir, terminar o anular los negocios jurídicos ${ }^{26}$.

Por tanto, en tratándose de las obligaciones de no hacer jurídico, consideramos que nuestro régimen contempla sólo la posibilidad de que el deudor resarza al acreedor, mas no sería dable que se dé por terminado el acto jurídico que el primero se comprometió a no otorgar o celebrar.

\section{2 ¿Por qué el convenio arbitral no genera obligaciones negativas?}

Estimamos que el convenio arbitral tampoco genera obligaciones negativas. Eso se debe a que el régimen previsto en la LAM para los casos de "incumplimiento" del convenio arbitral difieren del régimen que es propio de las obligaciones de no hacer, ya que al "incumplir" el convenio arbitral no se debe resarcimiento alguno al "acreedor".

La contravención de una obligación de no hacer jurídico sólo puede dar lugar al resarcimiento de los perjuicios causados al acreedor. Según explicamos, consideramos que no sería dable que el acto jurídico otorgado o celebrado en contravención de una obligación de no hacer pueda ser disuelto, ya que ello no verificaría ninguna de las causales de disolución de los negocios jurídicos y sería contrario al postulado de relatividad.

\footnotetext{
25. G. OsPinA FERnÁNDEZ y E. Ospina Acosta, Teoría general del contrato y del negocio jurídico, Temis, 2000 , p. 358.

26. Ídem, p. 508
} 
Entonces, cabe preguntarse si la condena en costas impuesta al litigante que acude a la justicia ordinaria a pesar de existir un convenio arbitral vendría a representar el resarcimiento que se tendría que pagar por incumplir con una obligación de no hacer.

Hay razones para pensar que la condena en costas no es equiparable al resarcimiento que aplicaría si el convenio arbitral en efecto generara obligaciones negativas. Eso se debe a que la condena en costas procesales es una institución distinta a la indemnización de daños y perjuicios.

En nuestro ordenamiento jurídico las costas procesales y la indemnización de daños y perjuicios son instituciones jurídicas distintas. En efecto, las costas procesales constituyen los gastos legales que hacen las partes y deben satisfacerse con ocasión de un procedimiento judicial, comprenden (los) honorarios de los abogados defensores [...]. La indemnización de perjuicios, en cambio, es el resarcimiento económico a la víctima por males o injurias que se le ha causado, resarcimiento que no se satisface con el pago de las costas procesales ${ }^{27}$.

La condena en costas no es una especie de resarcimiento de daños y perjuicios, sino que es una clase de sanción que se impone al litigante que ha obrado con deslealtad. Según ha sostenido la jurisprudencia, la condena en costas "procede cuando se ha litigado contra expresas normas legales, cuando no se ha aportado prueba alguna que respalde las pretensiones del litigante o cuando haya mala intención de causar infundadamente perjuicio a la parte" 28 . Lo mismo reza el artículo 284 del COGEP. En cambio, el resarcimiento de daños y perjuicios tiene por finalidad principal dejar a la víctima en la situación en la que habría estado en ausencia del ilícito.

Siendo así, es posible "incumplir" un convenio arbitral sin merecer una condena en costas. Piénsese, por ejemplo, en el caso

27. Primera Sala de lo Civil y Mercantil de la Corte Suprema de Justicia, Fallo No. 334-99, RO No. 257 , 19/08/1999.

28. Corte Suprema de Justicia, Fallo, Gaceta Judicial, Serie XIII, No. 8, p. 1647, 13/03/1980. 
de que el convenio arbitral sea de tal modo ambiguo que el actor considere ni siquiera cumple con los elementos esenciales para ser considerado tal. Si eso ocurriera, no podría decirse que la intención de litigante fue causar perjuicios de manera infundada a su contraparte o que su actuar fue temerario. En ese caso, si la otra parte se excepcionara con la existencia del convenio arbitral, la demanda no prosperaría, pero tampoco procedería la condena en costas.

Determinar si se está en presencia de un convenio arbitral no siempre es sencillo. Si siempre fuera fácil, nuestro legislador no habría debido consagrar instituciones como la del favor arbitralis, por ejemplo.

El motivo para imponer una condena en costas no sería el "incumplimiento" del convenio arbitral per se, sino el haber obrado con deslealtad. Si una parte acudiera ante los jueces ordinarios a pesar de existir un convenio arbitral claramente válido, habría razones para pensar que obró de manera temeraria y, por tanto, podría justificarse la condena en costas. Pero esa condena debería estar precedida de un análisis más profundo que el determinar si existe o no un convenio arbitral.

La solución que nuestra normativa da en el caso de que se "incumpla" el convenio arbitral es distinta que la que aplicaría si dicho convenio creara obligaciones de no hacer. Por lo tanto, no es cierto que el convenio arbitral genere obligaciones negativas.

\section{5. ¿QUÉ SON LOS DERECHOS POTESTATIVOS?}

En esta sección explicaremos por qué, en nuestra opinión, el convenio arbitral genera derechos potestativos. Estimamos que esa es la posición que mejor explica los efectos del convenio arbitral. Para eso debemos revisar cuál es el concepto de derecho potestativo y cuáles son sus clases. 
Según ALESSANDRI, gran parte de la doctrina moderna reconoce categoría de derecho subjetivo al poder que, por efecto de una relación determinada, tiene el titular para provocar, por su propia y exclusiva voluntad, es decir, por un acto unilateral, un cambio en la situación jurídica del sujeto pasivo. Se denomina a esos poderes "derechos potestativos" 29 .

Derechos potestativos son aquellos que, a la vez, no implican un deber. Se los ha definido como aquellos que confieren al sujeto la facultad de provocar un determinado efecto jurídico si así lo quiere $^{30}$.

\subsection{Diferencias entre derechos de crédito y derechos potestativos}

Los derechos de crédito y los derechos potestativos son clases de derechos subjetivos. Por derechos subjetivos entendemos aquéllas "facultades o poderes de que son titulares las personas y cuya función es la satisfacción de sus necesidades"31.

Las diferencias entre los derechos de crédito y los derechos potestativos son pocas, pero trascendentes. La primera diferencia entre los derechos de crédito y los derechos potestativos es que los primeros tienen una obligación correlativa, mientras que los segundos no, sino una simple relación de sujeción o sometimiento. El sujeto pasivo de un derecho potestativo nada puede hacer para evitar que su titular haga uso de su derecho, ya que tal ejercicio no depende del primero. En cambio, en principio se requiere del consentimiento del sujeto pasivo de un derecho de crédito para que su titular pueda ejercerlo.

La segunda diferencia es que la forma en la que se cumplen los derechos potestativos es a través de un acto jurídico unilateral. Así, por ejemplo, la facultad que tiene quien recibe una oferta de

29. A. Alessandri, M. Somarriva y A. Vodanovic, Tratado de las obligaciones: de las obligaciones en general y sus diversas clases, Jurídica de Chile, 2da. Ed., 2001, pp. 8-10.

30. G. Cabanellas, N. 8, Tomo. III, p. 161.

31. A. VAlEnCIA ZEA, Derecho civil: parte general y personas, Temis, 1997, p. 232. 
aceptarla o no puede ser ejercida sin que requiera del concurso del oferente. Por otro lado, quien tiene derecho a la observancia de una prestación verá su acreencia satisfecha mediante el pago, que es un acto jurídico generalmente bilateral ${ }^{32}$.

La tercera diferencia que resulta importante para efectos de nuestro trabajo es que los derechos de crédito se extinguen por los modos de extinguir las obligaciones previstos en el artículo 1583 y siguientes del Código Civil. La extinción de los derechos potestativos está sujeta a un régimen diferente.

\subsection{Clases de derechos potestativos}

Se divide a los derechos potestativos en estrictos y en facultades de poder. Los derechos potestativos estrictos confieren una potestad para crear un efecto jurídico por la sola y exclusiva voluntad de su titular. Por otra parte, las facultades de poder son aquéllas que conceden potestad para "celebrar contratos o actos jurídicos unilaterales que normalmente no trascienden de la esfera jurídica de quien los celebra; pero, en forma tal, que sus efectos se hacen extensivos al patrimonio de otra persona"33.

Se considera que los derechos potestativos se caracterizan por ser su eficacia automática, por no requerir de acción alguna de su titular, por regla general, y porque consisten en el derecho de producir un derecho.

A su vez, los derechos potestativos estrictos son de tres clases: los constitutivos, los modificativos y los cancelatorios o negativos. Los constitutivos son aquellos que dan origen a un derecho subjetivo, como el de aceptar una oferta, en tratándose de los derechos personales. Los modificativos son aquellos que permiten modificar una relación jurídica, como ocurre con el derecho de opción del acreedor de una obligación alternativa. Finalmente, los nega-

32. Es claro que hay muchos otros modos de extinguir las obligaciones. Sin embargo, el pago es el modo de extinguir en el que la obligación cumple el fin para el que fue creada. El pago es generalmente un acto bilateral, especialmente cuando se trata de obligaciones de dar.

33. Los primeros cuatro numerales han sido tomados de la obra de G. CABANELLAs, N. 8, Tomo III, p. 161. 
tivos son aquellos que tienden a poner término a una obligación, y pueden impedir que surta efecto la voluntad ajena. Se considera como derecho potestativo a las excepciones procesales.

En nuestra opinión, la facultad de oponer la excepción de existencia del convenio arbitral es un derecho potestativo. Como es sabido, las excepciones son aquellos medios de defensa opuestos por el demandado para, ya sea, impedir que la acción sea admitida a juicio o para obtener que sea rechazada total o parcialmente en definitiva. Las primeras se conocen como excepciones dilatorias y las segundas se denominan excepciones perentorias.

Si las acciones son los medios judiciales que la ley en manos de los litigantes para que puedan hacer efectivas sus reclamaciones ante los Tribunales, las excepciones representan los medios de defensa colocados al alcance de los amenazados por la acción ${ }^{34}$.

Deducir excepciones puede modificar la situación jurídica del actor y es de ejercicio facultativo. Modifica la situación jurídica del actor porque puede conducir a que su demanda sea rechazada, a más de cambiar el thema decidendum y, por tanto, el tema de prueba. Puede extinguir la acción para exigir ciertos derechos, como cuando se alega la prescripción como defensa; puede ser un requisito para extinguir derechos de crédito, como cuando se aduce la compensación como excepción; e incluso puede anular actos jurídicos, como cuando el perjudicado por un acto viciado por una causal de nulidad relativa se excepciona con la nulidad antes de que el acto sea saneado por el transcurso del tiempo.

Además, el deducir excepciones es una carga procesal. No puede forzarse al demandado a presentarlas, y el hacerlo le conviene a él únicamente. Por tanto, el presentar excepciones le es facultativo.

34. Corte Suprema de Justicia, Fallo, Judicial, Año XLVI, Serie X, No. 3, p. 2185, 07/10/196. (Voto salvado). 
Siendo así, las excepciones procesales comparten las características esenciales de los derechos potestativos. En consecuencia, todo acto que faculte a las partes a deducir una determinada excepción creará a su favor un derecho potestativo.

\section{El CONVENIO ARBITRAL GENERA DERECHOS POTESTATIVOS}

Según explicamos en nuestra introducción, no existe mayor discrepancia en cuanto a cómo se debe describir los efectos de un convenio arbitral. Una vez que se celebra un pacto arbitral, si la otra parte presenta una demanda ante la justicia estatal para tratar un asunto que se ha sometido a arbitraje, la otra parte puede deducir la excepción de existencia de convenio arbitral. Según el COGEP, esa es una de las excepciones previas que el demandado puede oponer $^{35}$. Si el juez acepta la excepción, se pone fin al proceso.

Es cierto que las partes acuerdan someter sus controversias a arbitraje y también es cierto que el convenio atribuye competencia al tribunal arbitral. Sin embargo, el derecho que las partes adquieren no es otro que el impedir que la demanda de su contraparte ante la justicia estatal prospere. Para BrISEÑO SIERRA, "el compromiso $^{36}$ produce las excepciones de incompetencia y litispendencia, si durante él se promueve el asunto ante un tribunal ordinario" $^{\prime 37}$.

Si es que las partes tienen el derecho de defenderse en un proceso con el objeto de que la demanda incoada por la otra parte sea archivada, dependiendo el ejercicio de ese derecho exclusivamente de la voluntad de su titular y teniendo una eficacia casi automática, entonces ese derecho es una excepción procesal.

35. COGEP, Artículo 153(10), RO Sup. No. 506, 22/05/2015.

36. A pesar de que el autor se refiere al compromiso arbitral, lo que menciona al respecto resulta aplicable a lo que nosotros entendemos por convenio arbitral.

37. H. BRISEÑo SIERRA, El arbitraje comercial: doctrina y legislación, Limusa, 1999, p. 33. 
Siendo así, concluimos que el convenio arbitral genera derechos potestativos. No crea derechos de crédito ni extingue facultad alguna.

La excepción que les es dada a las partes, a pesar de las múltiples denominaciones que se le ha dado, según hemos visto, es una de tipo dilatorio, ya que en nada impide que la pretensión respectiva pueda ser conocida nuevamente, eso sí, ante el tribunal arbitral competente. Según la LAM, se denomina "excepción de existencia de convenio arbitral", que no es lo mismo que denominarla excepción de "renuncia a la justicia estatal", como la llama GUASP, o excepción de "incompetencia", como la denomina BRISEÑO SIERRA.

\section{7. ¿QUÉ IMPLICA QUE EL CONVENIO ARBITRAL GENERE DERECHOS POTESTATIVOS?}

Hemos explicado por qué consideramos que el convenio arbitral genera derechos potestativos y no obligaciones. Hay, al menos, cuatro consecuencias prácticas de importancia que esa distinción trae consigo. Esas consecuencias derivan de las diferencias entre los derechos de crédito y los derechos potestativos que dejamos establecidas ya.

La primera distinción se refiere a la prescripción. Si el convenio arbitral generara obligaciones, estas, como casi cualquier otra obligación, podrían prescribir. La prescripción afectaría a la acción para exigir su cumplimiento, mas no a la existencia de la obligación en sí. Dado que el convenio arbitral genera derechos potestativos y no obligaciones, sería un sinsentido que quien acude ante la justicia estatal aduzca que la facultad que tiene su contraparte para deducir la excepción de convenio arbitral ha prescrito.

La segunda diferencia se refiere al modo en el que se ejerce el derecho de enervar la pretensión contraria. Si el convenio arbi- 
tral generara obligaciones positivas, observar su prestación, es decir pagarla, podría requerir de la aquiescencia del sujeto pasivo ya que el pago generalmente es un negocio jurídico bilateral. Por tanto, para poder ejercer el derecho derivado del convenio arbitral podría llegar a ser necesario el consentimiento del deudor. Dado que el convenio arbitral genera derechos potestativos, en ningún momento resulta relevante el consentimiento de la otra parte. Su suscriptor puede deducir la excepción de existencia de convenio arbitral por su sola voluntad. No necesita de la colaboración de la otra parte para hacerlo.

La tercera diferencia alude a la mora y la excepción de contrato no cumplido. Si el convenio arbitral generara obligaciones, al ser un negocio jurídico bilateral, llevaría envuelta la condición resolutoria tácita prevista en el Código Civil. El incumplimiento daría lugar a la acción resolutoria o la acción de cumplimiento forzado del contrato. Aplicaría la excepción de contrato no cumplido. Por lo tanto, habría que analizar si el contratante "incumplido" está en mora.

La última diferencia se relaciona con el cumplimiento forzado. Si el convenio arbitral generara obligaciones positivas, en ciertas hipótesis resultaría posible exigir su cumplimiento. Por tanto, podría forzarse a la contraparte a acudir a arbitraje. Según vimos, el convenio arbitral no otorga esa facultad; sólo permite al suscriptor impedir que prospere el juicio iniciado ante la justicia estatal.

\section{RESUMEN Y CONCLUSIONES}

Nuestro trabajo tuvo por objeto determinar cuál es, según el Derecho ecuatoriano, la naturaleza jurídica de los efectos que tiene para las partes suscribir un convenio arbitral. Expusimos tres explicaciones distintas: (i) la que sostiene que el convenio implica una renuncia a acudir ante la jurisdicción estatal; (ii) la que asevera que pactar una cláusula arbitral obliga a las partes a acu- 
dir a arbitraje y (iii) la que aduce que las partes de un pacto arbitral están obligadas a no acudir ante la justicia ordinaria.

Según expusimos, tenemos dos razones para discrepar con la primera de esas tesis. La primera razón es que la renuncia de los derechos absolutos es un acto unilateral. Por lo tanto, carecería de sentido que la renuncia tenga como fuente un negocio bilateral, como es el convenio arbitral. La segunda razón es que el convenio arbitral debe generar derechos, porque la ley permite renunciar al convenio arbitral y no se puede renunciar a lo que no se tiene. Si el convenio arbitral implicara únicamente una renuncia, una vez suscrito ya no habría a qué renunciar.

Además, explicamos por qué no es cierto que las partes estén obligadas a someter sus controversias a arbitraje. Siendo así, no es cierto que el convenio arbitral genere obligaciones de hacer.

El convenio arbitral tampoco genera obligaciones de no hacer, dado que el régimen de cumplimiento de las obligaciones de ese tipo es distinto a aquél contemplado para el caso de "incumplimiento" del convenio arbitral.

Finalmente, explicamos por qué, en nuestro sentir, el convenio arbitral genera derechos potestativos. Definimos a los derechos potestativos como aquellos de ejercicio facultativo, que traen como consecuencia la modificación de la situación jurídica del sujeto pasivo, pero sin depender en lo absoluto de la voluntad este. Expusimos por qué las excepciones procesales son derechos potestativos, y por qué, por tanto, el convenio arbitral, al generar la facultad de deducir la excepción de la existencia de convenio arbitral, genera un derecho potestativo para las partes, al cual se puede renunciar expresa o tácitamente.

Nuestro artículo pretendía presentar una explicación diferente sobre la naturaleza jurídica de los efectos que hemos mencionado. A pesar de que estamos conscientes que resulta contraria a la opinión mayoritaria, esperamos que contribuya de algún modo al debate con el fin de dilucidar la naturaleza y 
los efectos de una institución tan trascendente como lo es el convenio arbitral. 